\title{
Beitrag zur Ätiologie der Impetigo herpetiformis.
}

\author{
Von \\ Docent Prof. Dr. Anton Trýb. \\ (Aus der Dermatol. Universitätsklinik in Brünn.) \\ Mit 4 Textabbildungen.
}

In letzter Zeit wurden sämtliche bisher erschienenen Arbeiten über die Hebrasche Impetigo herpetiformis einer gründlichen Kritik unterzogen. Wir wissen, daß so manches zur Pemphigus-Gruppe gehörige Krankheitsbild früher hier eingereiht wurde. Durch die Zusammenfassung von Gavazzeni, Scherber u. a. wurde der klinische Begriff dieser Erkrankung definitiv klargelegt. Wir brauchen also nur ganz kurz die bekannten Tatsachen zu resumieren.

Die typische Primärefflorescenz der I. h. ist eine Pustel, niemals eine Vesikel. Die Pusteln erheben sich meist in herpetischer Anordnung auf einer mehr oder weniger entzündlichen Basis. Der ganze Prozeß beginnt meist in der Genitalgegend (Genitocruralfalte, Inguina) oder in der Axilla. Von da aus verbreitet er sich über die Haut des ganzen Körpers, in besonders ausgedehnten Fällen wird auch das Gesicht ergriffen. Nie wurden Pusteln an den Palmae oder Plantae beobachtet. Nach dem raschen Zusammenflicßen der Pusteln bilden sich blätterteigartige, mürbe Krusten, unter denen dic rote, meist nässende Papillarschicht liegt. Zur Fntwickelung von Geschwüren oder zur Narbenbildung nach dem Abheilen des Prozesses krommt es nie. Die Erkrankung kommt schubweise, unter Fieberparoxysmen und Schüttelfrost, und verläuft immer schwer, sehr oft tödlich.

Histologisch finden sich epidermoidale Pusteln, die meist ganz oberflächlich gelagert sind. Sonst sind, außer einem Ödem in den äußeren Epithellagen keine charakteristischen Befunde zu verzeichnen. Bakteriologisch ist der Pustelinhalt steril. Eiterkokken müssen stets als sekundäre Infektion angesehen werden.

Ätiologisch blieb die Erkrankung lange vollständig unklar und auch heute ist die Ursache noch lange nicht erwiesen. Der Umstand, daß die Krankheit meist bei schwangeren Frauen beobachtet wurde, führte dazu, daß man die Schwangerschaft ätiologisch verantwortlich machte, doch sprachen Fälle bei Nichtschwangeren, Virginen, ja sogar bei Männern ${ }^{1}$ ) gegen diese Theorie.

1) Dic maskuline Form wurde von Ehrmann u. a. bestritten. 
In neuester Zeit sind jedoch Arbeiten erschienen, welche in die Frage der Ätiologie der I. h. etwas mehr Licht bringen. Me yer und. Linser beobachteten einen Fall, der durch Einspritzungen von Serum normaler Schwangeren glänzend beeinflußt wurde. Dieser Umstand schien den Autoren genügend, die I. h. als eine Schwangerschaftstoxikose $\mathrm{zu}$ bezeichnen. Ziemann zieht auf Grund der bisherigen und eigenen Beobachtungen folgende Schlüsse: 1. I. h. ist eine Autotoxikose, bedingt durch Störungen des innersekretorischen Gleichgewichts. 2. Welche Organe derAusgangspunkt der

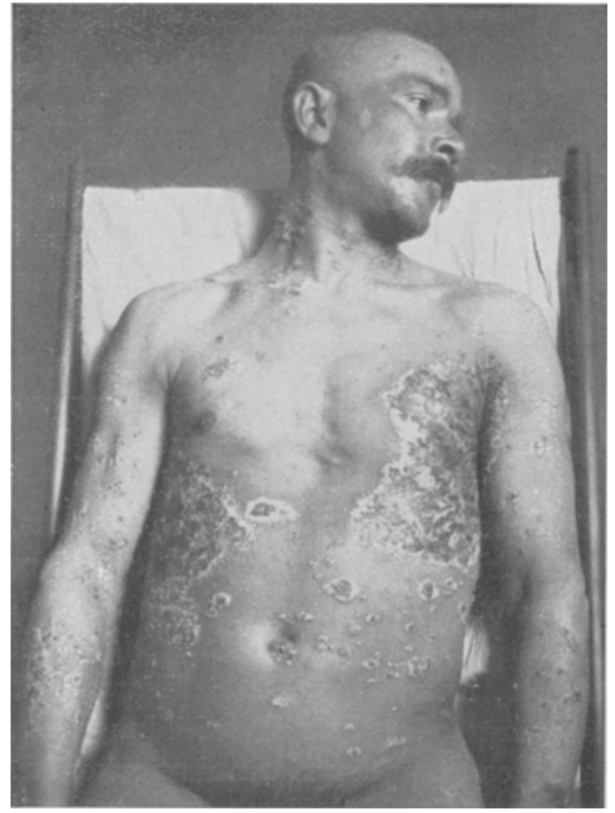

Abb. 1. Störung sind, wissen wir nicht. 3. Die Injektion von normalem Schwangerschaftsserum ist in jedem Falle von I. h. der Schwangeren zu versuchen.

Nun bleibt aber noch die Frage der Ätiologie der I. h. bei Nichtschwangeren und Männern offen. In der Literatur war Wechselmann der Erste, der serologische Untersuchungen bei I. $h$. anstellte und u.a. auf die Veränderungen der Hypophyse und Thymus hinwies.

Nun zu unserem Falle:

In dem großen Militärspitale in Pardubitz (Böhmen) wurde im Sommer 1917 ein schwer fiebernder Soldat Z. J. aufgenommen. Es war ein 32jähriger Bauer, Vater von zwei gesunden Kim. dern; seine Frau und die ganze Verwandtschaft ebenfalls gesund. Er selbst immer gesund, litt aber seit Jahren an starken Kopfsehmerzen.

Vor 11 Jahren erkrankte er zum erstenmale. Es zeigte sich in der Axillargegend ein Pustelausschlag, der sich nach etwa 6 Woehen über den ganzen Körper ausbreitete. Dabei hohes Fieber und Schüttelfrost. Die Krankheit dauerte fast 10 Monate, dann trat Besserung ein, neue Ausschläge bildeten sich nicht, die Haut wurde wieder normal, bis auf die Axillar- und Inguinalgegend, wo die Haut rot blieb und nach den Angaben des Patienten während der ganzen 11 Jahre nie normal wurde. Bei stärkerem Schwitzen kam es hier immer wieder zur Bildung einzelner Pusteln.

Die Anfälle mit starkem Fieber und Aussaat von Pusteln über den ganzen Körper wiederholten sich in anderthalbjährigen oder einjährigen Intervallen noch einige mal und dauerten immer 4 bis 8 Monate. Nach den Anfällen war der Mann immer stark herabgekommen, erholte sich jedoch immer wieder ziemlich rasch. 
Im Jahre 1915 war der Kranke nach einem Anfall, der über 1/2 Jahr daucrtc, fast ein Jahr gesund (bis auf die beschriebenen Veränderungen in der Axillarund Inguinalgegend), so daß er assentiert wurde und ins Feld kam. Nach fünfwöehigem Felddienst kam ein Anfall, der nur 7 Wochen dauerte und der sich nicht einmal über den ganzen Körper verbreitet hat. Nach Ausheilung im Feld. spitale diente er weitere 6 Monate im Felde, bis der Anfall kam, den wir jetzt vor uns haben.

Der Kranke fieberte mit minimalen Remissionen bis $40^{\circ}-41^{\circ}$, war jedoch stets bei Bewußtsein, hatte sogar ab und zu Appetit, und ist somatisch sowohl wie neurologisch ohne Befund.

Urin normal. Blutbild bis auf cine geringe Eosinophilie normal. WaR. negativ, ebenso Pirquet.

Dermatologischer Befund bei der Aufnahme: In der linken Achselhöhle sowie in der Mamillargegend ist die Haut in einer Ausdehnung von ca. 20 qcm entzündlich verändert, mit mürben gelblichen Krusten bedeckt. Die Ränder dicser Fläche weisen festonartig angcordnete Reste von zusammengeflossenen $\mathrm{Pu}$ steln auf, welche an der Peripherie herpetisch gruppiert sind. Ein gleicher, etwas kleinerer Herd ist in der Mamillarlinie rechts sichtbar. Außer dieser groBen Gruppe sind zahllose kJeine, typisch herpetiforme Herde über den Stamm, Hals und die oberen Extremitäten verstreut. Ihre Größe ist nach ihrem Alter verschicden. Das Gesicht und die unteren Extremi-

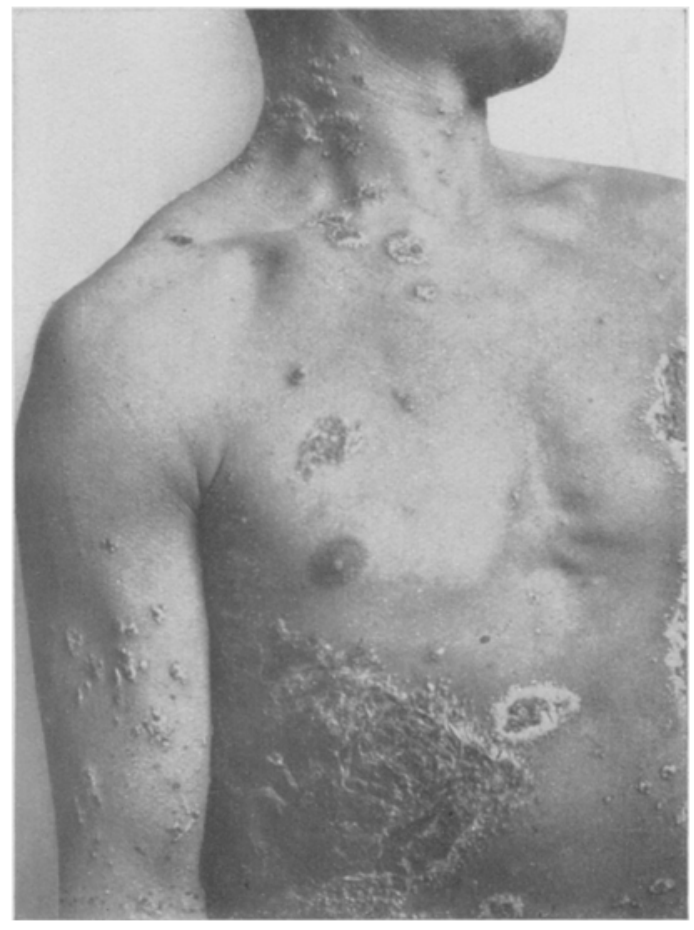

Abb. 2. täten sind frei. In den Genitocruralfalten ist dic Haut livid rot, obne Pustelbildung. Patient klagt über Jucken beim Aufsehießen der Efflorescenzen, jedoch ist dies nieht sehr schlimm. Wir sehen auch keine Kratzeffekte (Abb. 1 und 2).

Drei Wochen später ist der ganze Stamun mit blätterteigartigen, blaßgelben Krusten bedeckt, unter denen die Papillarschicht scharlachrot, nässend erscheint. An den frisch epithelisierten Stellen bilden sich immer wieder noue Pusteln. In der Gegend der beiden Claviculae und des Manubrium sterni sehen wir eine reichliche Aussaat von Pusteln, welche zusammenfließend bis erbsengroß werden und die ganz irregulär zerstreut sind (Abb. 3 und 4).

Histologisch können wir den Befunden von Du Mesnil u. a. nichts Neues beifügen. Es handelt sich eben um meist ganz oberflächlich gelagerte Epidermoidalpusteln, die bakteriologisch steril sind. 
Die Diagnose ist unbestreitbar, es kommt nichts anderes in Betracht. Im ganzen Bilde sehen wir als primäre Efflorescenzen typisch angeordnete Pusteln und ihre charakteristischen Veränderungen. Hohe, wochenlang dauernde Temperaturen, der cyklische Verlauf, das sowohl klinische als auch histologische und bakteriologische Bild. - Alles bestätigt nur unsere Diagnose.

Es handelt sich also um einen maskulinen Fall von Impetigo herpetiformis. Der Anfall dauerte diesmal fast 5 Monate. Nach dieser Zeit, als schon die Haut

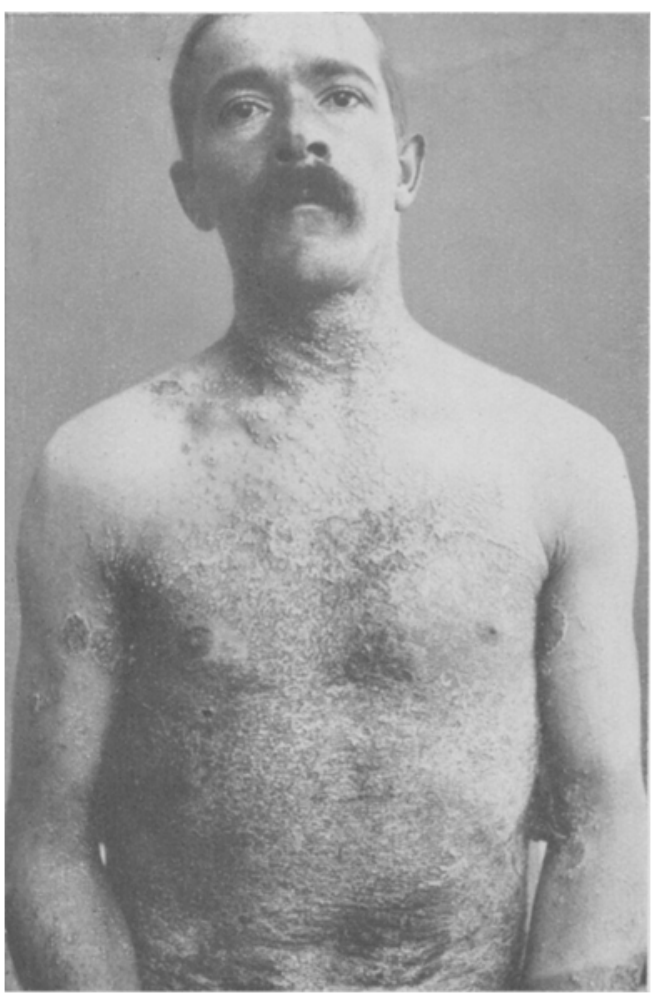

Abb. 3. des Stammes zur Norm zurückgekehrt war und die Temperatur $37^{\circ}$ nicht überschritt, klagte Patient, der beim besten Appetit war und sich im allgemeinen deutlich besserte, über großes Durstgefühl und große Mengen von Urin, die er täglich absondert. (Wir wollen noch erwähnen, daß auf der Höhe des Hautprozesses ziemlich viel Indican im Urin war, das später aber wieder verschwand, so daß der Urin vollständig ohne pathologische Beimischungen blieb.) Es stellte sich heraus, daß der Mann in 24 Stunden 6 bis 7 Liter Urin absondert welcher Zustand fast über vier Wochen dauerte, worauf auch diese Erscheinung allmählich verschwand. Patient gibt an, daß er von solcher Polyurie schon mehrmals im Anschlusse an seine Anfälle belästigt worden war.

Eine Röntgenaufnahme, die bei ihm sofort durchgeführt wurde, zeigte eine starke Vergrößerung der Hypophyse, was wir daraus schlossen, daß die Sella turcica mindestens zweimal so breit war als de norma und ihre Konturen ziemlich verwischt waren. Leider war es unmöglich verläßliche Hypophysenextrakte zu beschaffen. Auch Serum normaler Schwangerer war nicht erhältlich, und so beschränkte sich unsere Therapie intern auf Chinin, lokal auf Zinkschwefelpaste und Wilsonsche Salbe. Der Mann wurde auch so bis auf kleine Reste geröteter Haut in den beiden Axillae und Inguinen gesund und trotz aller fachärztlicher Gutachten wieder ins Feld geschickt. Von da kam er nach $3 / 4$ Jahren zufälligerweise wieder in unser Spital zurück in einem noch schwereren Zustande als zum erstenmal. Er blieb 3 Monate in Behandlung und wurde leider in moribundem Zustande seiner Familie übergeben, welche trotz alles Zuredens wünschte, den Mann nach Hause zu bekommen. Dort starb er, ohne daß wir die Sektion durchführen konnten. 
Wir publizieren diesen Fall aus folgenden Gründen: Erstens einmal dokumentiert er die Existenz einer Impetigo herpetiformis beim Manne.

Zweitens handelte es sich um Veränderungen der Hypophyse, welche vergrößert war und welche auch höchstwahrscheinlich die Anfälle von Diabetes insipidus verursachte. Eine andere Ursache läßt sich nicht annehmen.

Ohne uns in weitschweifende Konklusionen einzulassen, konstatieren wir diese Momente und stimmen Wechselmann vollständig bei in der Ansicht, daß man bei I. h. stets auf Veränderungen der Нypophyse und der Thymus. achten soll. Denn die Veränderungen, welchen die Hypophyse in der Schwangerschaft unterliegt, können die physiologischen Grenzen leicht überschreiten, und daB ähnliche pathologische Veränderungen dieser Drüse auch beim Manne vorkommen können ist

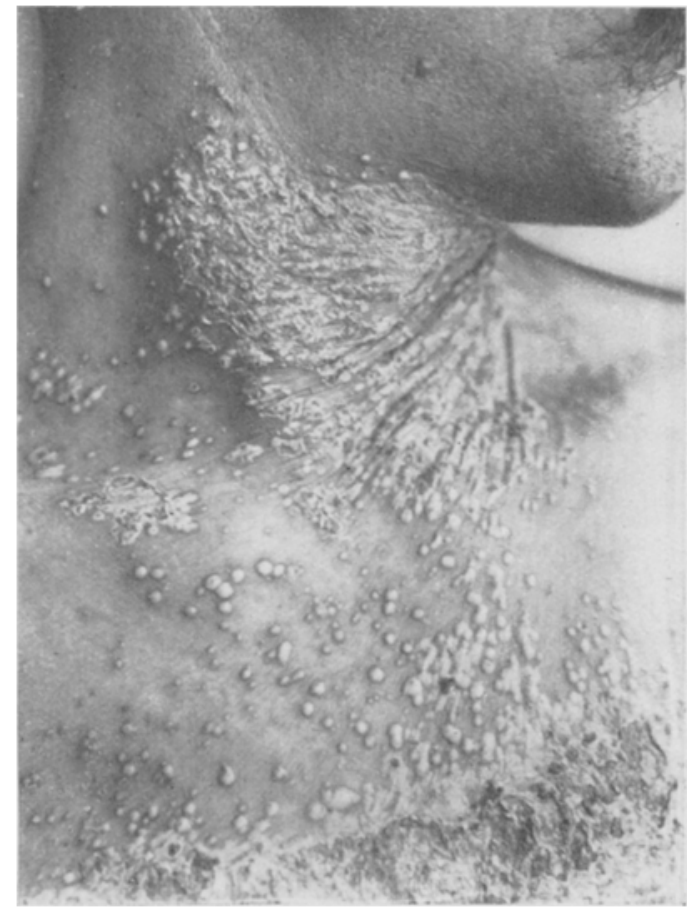

Abb. 4. klar. Daß3 solche die einzige Ursache der Imp. herp. wären, ist kaum anzunehmen, daß sie jedoch ein wichtiges Moment in ihrer Ätiologie bilden können, scheint auch unser Fall zu beweisen. Allerdings wird bei der Gravidität der drüsige Teil, beim Diab. insip. der Mittellappen der Hypophyse in Anspruch genommen, doch schon die topographischen Verhältnisse machen die Annahme wahrscheinlich, daß auch beide Lappen ergriffen sein können. 